\title{
Morphology-matching-based R-wave detection for noise-robust ECG gating
}

Takami Yoshida ${ }^{1 *}$, Taketo Kawakami ${ }^{2}$, Sojuro Kato ${ }^{2}$, Hidenori Takeshima', Makoto Hirohata', Shigehide Kuhara ${ }^{3}$

From 19th Annual SCMR Scientific Sessions

Los Angeles, CA, USA. 27-30 January 2016

\section{Background}

Accurate ECG R-wave detection is crucial for cardiac gating in MRI. However, in high-field MRI systems, it is hard to detect R-waves in ECG signals accurately, because the amplitude of the ECG signal may be smaller than that of the noise induced by the MRI system. To overcome this issue, existing studies have focused on (a) acquiring additional ECG signals or on (b) improving the R-wave detector to be robust against noise. In the first approach, ECG gating with a 12-lead ECG has been reported to have high accuracy [1]. However, due to ECG monitor limitations, this study utilizes a common dual-lead ECG. We propose a new morphology-matching-based R-wave detector for noise-robust ECG gating. The morphology is analyzed in filtered ECG signals, and the R-wave is detected by matching the input ECG signals to R-wave templates. The templates are updated when the MRI system is not scanning, and they contribute to robustness against patient variation and noise [1].

\section{Methods}

Dual lead ECG signals were recorded using a 3-T MRI system (Vantage Titan 3T, Toshiba Medical Systems Corporation) and an attached ECG monitor. We scanned

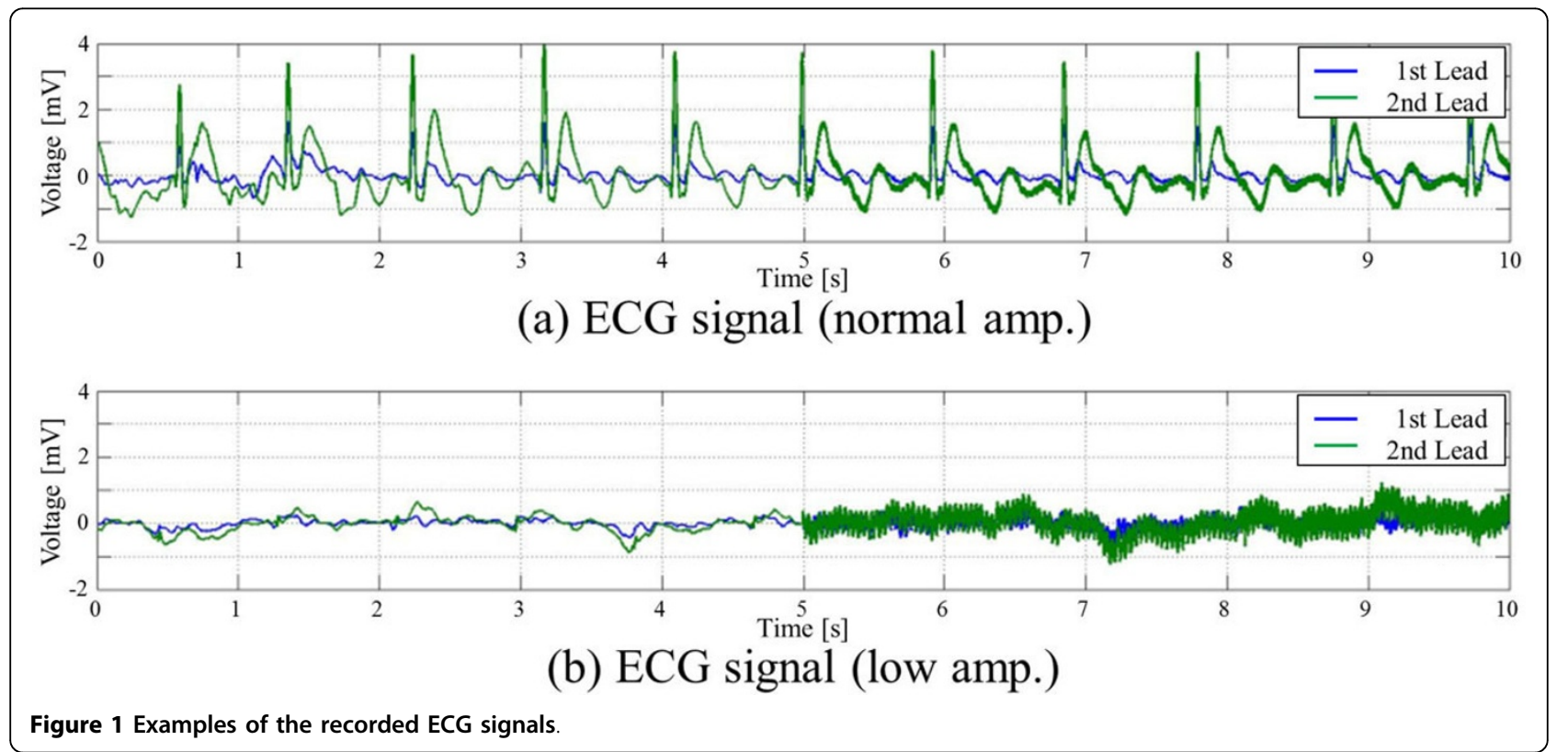

${ }^{1}$ Corporate Research \& Development Center, Toshiba Corporation, Kawasaki,

Japan

Full list of author information is available at the end of the article

(0) 2016 Yoshida et al. This is an Open Access article distributed under the terms of the Creative Commons Attribution License (http:// creativecommons.org/licenses/by/4.0), which permits unrestricted use, distribution, and reproduction in any medium, provided the original work is properly cited. The Creative Commons Public Domain Dedication waiver (http://creativecommons.org/publicdomain/ zero/1.0/) applies to the data made available in this article, unless otherwise stated. 


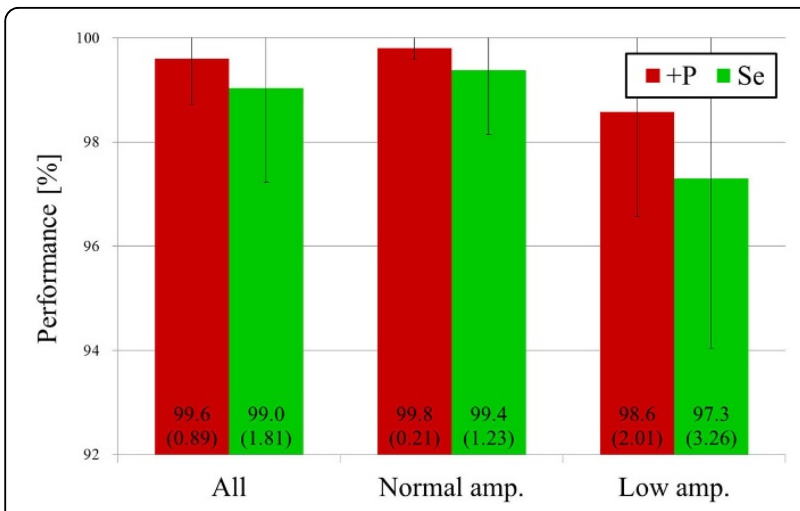

Figure 2 ECG gating performance (averages and standard deviations) for the proposed technique.

a total of 27 volunteers, including 5 volunteers with lowamplitude ECG waveforms ( $\mathrm{R}$-waves are less than $1[\mathrm{mV}])$. Fig. 1 shows examples of the recorded ECG signals. Each volunteer was scanned using 9 cardiac MRI sequences (Locator, Shimming, Map, axial multislice SSFP, Cine, T2WI, T1WI, perfusion, and LGE). The lengths of the ECG records of the volunteers ranged from $850 \mathrm{~s}$ to $1960 \mathrm{~s}$. The proposed R-wave detector processes ECG records using 4 modules: a filtering module, a first stage detection module, a template update module, and a second stage detection module. The filtering module accentuates the R-wave-related frequency components. The first stage detection module detects the peaks from the filtered ECG signals and sends the detected peaks to the template update module. The template update module updates the R-wave templates when the MRI system is not scanning. The second stage detection module then detects the R-waves using the adaptively updated templates.

\section{Results}

The proposed R-wave detector was evaluated using the records of above-mentioned 27 volunteers. Fig. 2 shows the positive predictive value $(+\mathrm{P})$ and sensitivity $(\mathrm{Se})$ for the proposed detector. As shown in Fig. 2, $+\mathrm{P}$ is higher than Se because the detection of an R-wave overlapped by noise is difficult. To improve Se further, noise suppression technique is promising.

\section{Conclusions}

The proposed method showed that R-wave detection using dual lead ECG can achieve $+\mathrm{P}$ of $99.6 \%$ and Se of $99.0 \%$. This method is expected to be clinically useful in cardiac MRI examinations, especially in MRI systems with field strengths of $3 \mathrm{~T}$ or more.

\section{Authors' details}

${ }^{1}$ Corporate Research \& Development Center, Toshiba Corporation, Kawasaki, Japan. ${ }^{2}$ MRI Systems Division, Toshiba Medical Systems Corporation, Otawara, Japan. ${ }^{3}$ Center for Medical Research and Development, Toshiba Medical Systems Corporation, Otawara, Japan.

Published: 27 January 2016

\section{Reference}

1. Tse Z, et al: JCMR 2013.

doi:10.1186/1532-429X-18-S1-P21

Cite this article as: Yoshida et al:: Morphology-matching-based R-wave detection for noise-robust ECG gating. Journal of Cardiovascular Magnetic Resonance 2016 18(Suppl 1):P21.
Submit your next manuscript to BioMed Central and take full advantage of:

- Convenient online submission

- Thorough peer review

- No space constraints or color figure charges

- Immediate publication on acceptance

- Inclusion in PubMed, CAS, Scopus and Google Scholar

- Research which is freely available for redistribution

Submit your manuscript at www.biomedcentral.com/submit
C Biomed Central 